\title{
A prospective study about the preoperative total blood loss in older people with hip fracture
}

This article was published in the following Dove Press journal:

Clinical Interventions in Aging

31 October 2016

Number of times this article has been viewed

\author{
Jie-Zhou $\mathrm{Wu}^{1,2, *}$ \\ Peng-Cheng Liu',* \\ Wei Ge $\mathrm{e}^{1,2}$ \\ Ming Cail \\ 'Department of Orthopedics, \\ Shanghai Tenth People's Hospital, \\ Tongji University School of Medicine, \\ Shanghai, ${ }^{2}$ The First Clinical Medical \\ College, Nanjing Medical University, \\ Nanjing, People's Republic of China \\ *These authors contributed equally \\ to this work
}

Purpose: Our study is to confirm that hemoglobin $(\mathrm{Hb})$ level is significantly reduced before operation in elderly patients with hip fracture and to specify potential amounts of bleeding and $\mathrm{Hb}$ decline in different types of fractures.

Methods: A prospective analysis was made on the clinical data of 349 patients with both a diagnosis of hip fracture and an operative delay of greater than 72 hours between April 2014 and February 2016. Hb concentration was measured on a daily basis before the surgery. Patients were grouped according to the type of fracture (intracapsular and extracapsular) for calculation of the total blood loss (TBL). All data analyses were done by SPSS version 21 software.

Results: There was a significant decrease preoperatively in the Hb concentration of nearly $21.55 \mathrm{~g} / \mathrm{L}$ (standard error of the mean [SEM] 7.67) in patients with extracapsular hip fractures and nearly $15.63 \mathrm{~g} / \mathrm{L}$ (SEM 6.01) in patients with intracapsular hip fractures. The preoperative TBL in patients with extracapsular fracture was significantly larger compared to that in patients with intracapsular fracture $(790.3 \mathrm{~mL}$ and $581.7 \mathrm{~mL}$, respectively, $P<0.05$ using Student's $t$-test). We found no significant difference in the preoperative TBL between the male and female groups.

Conclusion: Hip fracture patients have an obvious blood loss after the injury, yet prior to the surgery the $\mathrm{Hb}$ levels were found to be normal. Anesthetic and orthopedic staff should pay additional attention to the problem of low preoperative $\mathrm{Hb}$ concentration, even if the initial $\mathrm{Hb}$ level was apparently normal.

Keywords: hip fracture, blood loss, anemia, preoperation, hemoglobin

\section{Introduction}

Hip fracture is a common fracture secondary to a fall in aged population. ${ }^{1}$ As a consequence of global population aging, the incidence of hip fracture has been increasing. ${ }^{2-4}$ However, most attention regarding perioperative hemorrhage in elderly patients with hip fracture is paid to intraoperative and postoperative hemorrhage, ${ }^{5}$ while studies on concealed hemorrhage before fracture operation are limited. ${ }^{6,7}$

It has been reported that hemoglobin $(\mathrm{Hb})$ level shows a sustained downward trend after hip fracture. ${ }^{6}$ It suggests a potential anemia caused by persistent hemorrhage after hip fracture. However, we still do not know the amount of bleeding and $\mathrm{Hb}$ level changes in different types of fractures. Previous studies have also showed that low $\mathrm{Hb}$ level is positively correlated to poor prognosis after hip fracture. ${ }^{8-11}$ They suggest that in order to reduce intraoperative risk and improve postoperative prognosis, it is important to actively pay attention to and correct low $\mathrm{Hb}$ level in elderly patients with hip fracture. ${ }^{12,13}$

For this reason, we hypothesized that a large drop in $\mathrm{Hb}$ could originate from the secondary hemorrhage following initial trauma. Our study is to confirm that $\mathrm{Hb}$ level
Correspondence: Ming Cai Department of Orthopaedics, Shanghai Tenth People's Hospital, Tongji University School of Medicine, No 30I Yanchang Middle Road, Zhabei, Shanghai 200072, People's Republic of China Tel +86 I386147208

Email orthopedics_dsyy@163.com

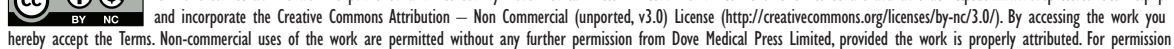
for commercial use of this work, please see paragraphs 4.2 and 5 of our Terms (https://www.dovepress.com/terms.php). 
is significantly reduced before operation in elderly patients with hip fracture, and to specify potential amounts of bleeding and $\mathrm{Hb}$ decline in different types of fractures. It will provide a clinical basis for timely detection and correction of low $\mathrm{Hb}$ level in elderly patients. ${ }^{14}$

\section{Patients and methods}

We conducted this prospective study at Shanghai Tenth People Hospital (level-one trauma center) where patients with a diagnosis of a hip fracture and an operative delay of greater than 72 hours were studied prospectively between April 2014 and February $2016 .{ }^{15}$ The study protocol was approved by the Institutional Ethics Committee at Shanghai Tenth People Hospital. Written informed consent was obtained from all patients included in this study.

The fractures included unilateral intra and extracapsular fractures of the proximal femur but excluding subtrochanteric fractures, which were considered to be higher energy injuries involving higher volume of blood loss. Patients were excluded from the study if they were aged below 60 years, operated within 72 hours of admission, and had a documented diagnosis of anemia or gastrointestinal hemorrhage. Patients were also excluded if they had another source of hemorrhage or were receiving anticoagulation therapy including vitamin $\mathrm{K}$-antagonists, direct thrombin inhibitors, direct factor Xa inhibitors, and platelet aggregation inhibitors.

All the patients were managed according to the same hip fracture pathway protocol after admission. ${ }^{16}$ According to protocol, standardized fluid and transfusion procedures were enforced. ${ }^{17}$ They received $1 \mathrm{~L}$ of normal saline every 8 hours prior to surgery and were transfused with blood if the level of $\mathrm{Hb}$ fell below $90 \mathrm{~g} / \mathrm{L}$ at any point during their admission. ${ }^{14,18}$

$\mathrm{Hb}$ concentration was measured on a daily basis before the surgery. The first time and the last one was on admission and immediately prior to surgery, giving a total of four $\mathrm{Hb}$ measurements (days 1-4). Measurement was by venous sampling with Hemocue and analyzing by the methemoglobin method.
All the data were prospectively recorded by the hospital staff in the patient record. Fracture classification (from the radiologist report), serial $\mathrm{Hb}$ levels, and patient comorbidities (from admission records) were recorded. Weight and height were assessed by the admitting doctor. If the patients could not be weighed on a weighing machine, their weight was estimated by using a gender- and age-dependent mean height-to-weight relationship. ${ }^{19}$

The total blood loss (TBL) was the primary outcome. Patients were grouped according to the type of fracture (intracapsular and extracapsular) for calculation of the TBL. TBL was calculated based on the $\mathrm{Hb}$ level, the $\mathrm{Hb}$ concentration on admission $\left(\mathrm{Hgb}_{\text {adm }}\right)$ and the final $\mathrm{Hb}$ concentration immediately prior to surgery $\left(\mathrm{Hgb}_{\text {fin }}\right)$, the number of transfusions $\left(\mathrm{Hgb}_{\text {trans }}\right)$, and the estimated blood volume. ${ }^{20}$ Considering the effects of dehydration on the level of $\mathrm{Hb}$ on admission, the $\mathrm{Hb}$ level on admission was corrected by a factor of 0.9 , in order to simulate $10 \%$ dehydration in all patients. The blood volume was determined according to gender, body mass, and height. The formulae (Nadler's formula) used for the calculations are presented in Figure 1. ${ }^{21}$

All data analyses were done by SPSS version 21 software, and we used Student's $t$-test for statistical analysis. A $P$-value $<0.05$ was taken as significant.

\section{Results}

A total of 349 patients (203 females, 146 males), with 164 patients in the intracapsular fracture group and 185 in the extracapsular fracture group, met the inclusion criteria and, therefore, formed the study group from April 2014 to February 2016. The mean time from admission to surgery was 4 days (range 3-5). Baseline data of the included patients are shown in Table 1.

Figure 2 shows the on admission, day 2, day 3, and final $\mathrm{Hb}$ levels of 349 patients with intracapsular and extracapsular fractures. Figure 3 shows the lowest final recorded $\mathrm{Hb}$ level prior to surgery was $106.75 \mathrm{~g} / \mathrm{L}$ (standard error of the mean [SEM] 7.67) for patients with extracapsular fractures and $112.85 \mathrm{~g} / \mathrm{L}$ (SEM 7.59) for those with intracapsular fractures. The average preoperative drop in $\mathrm{Hb}$ for the extracapsular and

$$
\begin{gathered}
\text { Blood volume }(\mathrm{L})=\text { height }(\mathrm{m})^{3} \times 0.356+\text { weight }(\mathrm{kg}) \times 0.033+0.183 \text { for females } \\
\text { Blood volume }(\mathrm{L})=\text { height }(\mathrm{m})^{3} \times 0.367+\text { weight }(\mathrm{kg}) \times 0.032+0.604 \text { for males } \\
\mathrm{Hgb}_{\text {loss }}=\text { blood volume } \times\left(\mathrm{Hgb}_{\text {adm }}-\mathrm{Hgb}_{\text {fin }}\right)+\mathrm{Hgb}_{\text {trans }} \\
\text { Blood loss in } \mathrm{mL}=\left(\mathrm{Hgb}_{\text {loss }} / \mathrm{Hgb}_{\mathrm{adm}}\right) \times 1,000
\end{gathered}
$$

Figure I Hemoglobin (Hgb) dilution formula and Nadler's formula for blood volume.

Abbreviations: $\mathrm{Hgb}_{\text {adm }}$, hemoglobin value on admission; $\mathrm{Hgb}_{\text {fin }}$, hemoglobin value immediately prior to surgery; $\mathrm{Hgb}_{\text {trans }}$, total amount of hemoglobin ( $\mathrm{g}$ ) in the transfused red blood cells before the measurement of $\mathrm{Hgb}_{\mathrm{fin}} ; \mathrm{Hgb}_{\text {loss }}$, calculated total hemoglobin loss $(\mathrm{g})$. 
Table I Details of the 349 patients with hip fracture

\begin{tabular}{ll}
\hline Patient characteristics & Mean (Range) \\
\hline $\begin{array}{l}\text { Median age, years (range) } \\
\text { Gender }\end{array}$ & $75(69-8 \mathrm{I})$ \\
$\quad$ Male & 146 \\
$\quad$ Female & 203 \\
Median weight, $\mathrm{kg}$ (range) & $64(57-7 \mathrm{I})$ \\
Median height, cm (range) & $162(156-168)$ \\
Fracture type, $\mathrm{n}(\%)$ & \\
$\quad$ Intracapsular & $164(47)$ \\
Extracapsular & $185(53)$ \\
Median delay to surgery, days (range) & $4(3-5)$ \\
\hline
\end{tabular}

intracapsular fracture groups were $21.55 \mathrm{~g} / \mathrm{L}$ (SEM 7.67) and $15.63 \mathrm{~g} / \mathrm{L}$ (SEM 6.01), respectively, and the difference was statistically significant $(P<0.05)$. On the basis of the fracture types, the preoperative TBL values, corrected for $10 \%$ dehydration, were found to vary from $378 \mathrm{~mL}$ to $1,013 \mathrm{~mL}$. Figure 4 shows the mean preoperative TBL was $790.3 \mathrm{~mL}$ (standard deviation [SD] 103.2) in the extracapsular fracture group and $581.7 \mathrm{~mL}$ (SD 78.4) in the intracapsular fracture group. Difference in means was $280.6 \mathrm{~mL}$ (95\% confidence interval [CI] 61.7-349.5; $P=0.005$, two-sided $t$-test). Figure 5 shows the details of the results based on gender, and the differences in the preoperative TBL values between the groups did not reach statistical significance.

\section{Discussion}

There was a significant decrease preoperatively in the $\mathrm{Hb}$ concentration of nearly $21.55 \mathrm{~g} / \mathrm{L}$ (SEM 7.67) in patients with extracapsular hip fractures and nearly $15.63 \mathrm{~g} / \mathrm{L}$ (SEM 6.01) in those with intracapsular hip fractures. The biggest difference in $\mathrm{Hb}$ level was observed between the values taken on the first day and those taken on the next day.

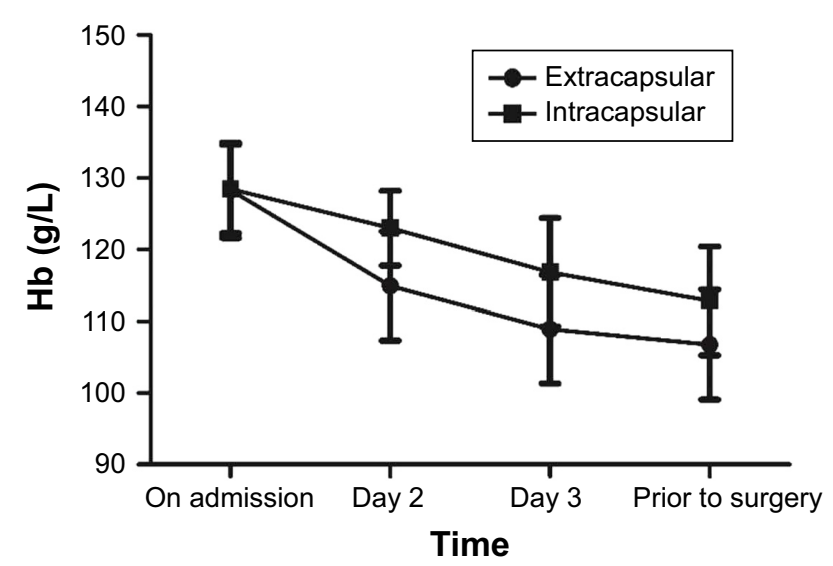

Figure $\mathbf{2}$ Line graph showing mean hemoglobin concentration for extracapsular and intracapsular fracture groups from admission to the surgery day.



Figure 3 The mean hemoglobin results for extracapsular and intracapsular hip fracture patients on admission and prior to surgery.

Considering that we had ruled out patients who had another source of hemorrhage or anticoagulation therapy, the blood loss that occurred between the time of fracture and the time of operation could only be the reason for the decrease of $\mathrm{Hb}$ level. Smith et $\mathrm{al}^{5}$ also showed that a large proportion of the blood loss happened preoperatively. So, we hypothesized that this large drop in $\mathrm{Hb}$ level could originate from the secondary hemorrhage following initial trauma. Compared to the postoperative $\mathrm{Hb}$ drops, which were the focus of other studies, the preoperative decrease in $\mathrm{Hb}$ was obviously higher than the decline after surgery. ${ }^{8,20}$ This finding implies that the major blood loss, excepting the intraoperative blood loss of hip fracture, occurred prior to surgery.

$\mathrm{Hb}$ is one of the best indicators for calculating the preoperative TBL in hip fracture patients. ${ }^{9,22}$ However, the relationship between the $\mathrm{Hb}$ level and the preoperative TBL needs be explored deeply. It is influenced and controlled by many factors, such as dehydration on admission.

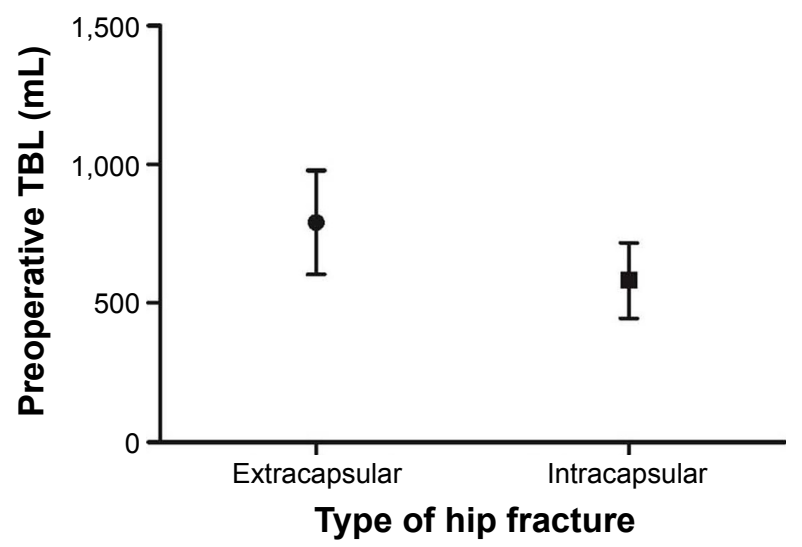

Figure 4 Box plot showing median value of the preoperative TBL in extracapsular and intracapsular fracture groups. Abbreviation: TBL, total blood loss. 




Figure 5 Median value of the preoperative TBL in male and female hip fracture groups.

Abbreviation: TBL, total blood loss.

It is common for hip fracture patients to be dehydrated on arrival to hospital. Due to the large loss of body fluids during the time from fracture to admission, dehydration could have caused an exaggeration of the admission $\mathrm{Hb}$ value. Meanwhile, previous studies have shown that the infusion of intravenous fluids would cause the falling of Hb levels. ${ }^{6}$ Similar finding was also observed in this study. So, the admission $\mathrm{Hb}$ level may not represent the true $\mathrm{Hb}$ value for that patient. The admission $\mathrm{Hb}$ should be interpreted discreetly and one should consider that patients may be more anemic than is immediately apparent.

Our study is the first to evaluate the TBL before surgery in elderly patients with hip fracture. The accuracy of the calculated preoperative TBL lies on the validity of the $\mathrm{Hb}$ values on admission, the final $\mathrm{Hb}$ levels, and the estimated blood volume. Similar methods have been reported in other studies. $^{5}$

The preoperative TBL in connection with the types of hip fracture was substantial. The preoperative TBL was significantly more for the extracapsular fracture patients than for the intracapsular fracture patients $(790.3 \mathrm{~mL}$ and $581.7 \mathrm{~mL}$, respectively, $P<0.05$, Student's $t$-test). The greater bone surface area in the extracapsular group may be responsible for this result. The loss of blood was also associated with increased length of delay to surgery. ${ }^{15}$

We found no significant difference $(P>0.05)$ in the preoperative TBL between the male and female groups, and the clinical significance of this finding is debatable. ${ }^{13}$ We cannot rule out the possibility that gender is implicated in this difference in the preoperative TBL.

Previous studies have found that there was some association between anemia and poor functional outcome and delirium in patients with hip fracture, such as higher postoperative $\mathrm{Hb}$ level may improve functional recovery after hip fracture repair, therefore it is important to maintain $\mathrm{Hb}$ at an appropriate level. ${ }^{9}{ }^{13}$ Some studies have advocated an increase in the threshold of blood transfusion in the preoperative period in order to improve the safety of operation. ${ }^{23}$ Based on the findings of our study, it could be arguable whether to transfuse patients with $\mathrm{Hb}$ level less than $100 \mathrm{~g} / \mathrm{L}$ before surgery, in order to prevent $\mathrm{Hb}$ level falling below $80 \mathrm{~g} / \mathrm{L}$ during or after surgery. In our hospital, an $\mathrm{Hb}$ concentration of $100 \mathrm{~g} / \mathrm{L}$ or more is considered as an acceptable threshold for surgery. However, most patients with hip fracture are elderly patients whose basal ability of organ systems has been reduced. This study has shown that $90 \%$ of patients reached the $\mathrm{Hb}$ threshold for surgery on admission, but only $70 \%$ were above the safety level according to the final test results.

Compared with previous studies, the present study has several advantages as the study was a prospective study. Additionally, all the patients treated with rehydration were according to the same protocol. The weakness of this study was that patients taking aspirin or other antiplatelet agents regularly were excluded, as hip fracture in such patients may result in greater drop in $\mathrm{Hb}$ levels than those not taking it. Excluding these patients would, in fact, decrease the average drop in $\mathrm{Hb}$ levels and the preoperative blood loss. Another weakness of this study was that the preoperative TBL was calculated based on several clinical parameters which could be a source of error. The initial dehydration and the rehydration following admission may interfere with the accuracy of $\mathrm{Hb}$ measurements, but it should not affect the difference because all the patients were treated with the same protocol.

\section{Conclusion}

We found that hip fracture patients often suffer from an obvious blood loss that occurs after the injury, yet prior to the surgery the Hb levels were found to be normal. This could pose a threat to the safety of the subsequent operation in this patient group. ${ }^{24}$ Some patients are actually anemic but are not identified prior to their surgery. So anesthetic and orthopedic staff should pay additional attention to the problem of low preoperative $\mathrm{Hb}$ concentration, even if the initial $\mathrm{Hb}$ level was apparently normal. ${ }^{25}$ In our view, frequent measurements of $\mathrm{Hb}$ levels are necessary to avoid anemia and improve the safety of surgery not only on admission. Measures which can reduce the preoperative TBL need to be investigated further in those with hip fractures.

\section{Acknowledgment}

This work was supported by the Natural Science Foundation of Shanghai, People's Republic of China (grant no 14ZR1432600). 


\section{Disclosure}

The authors report no conflicts of interest in this work.

\section{References}

1. Cooper C, Campion G, Melton LJ. Hip fractures in the elderly: a worldwide projection. Osteoporos Int. 1992;2(6):285-289.

2. Berry SD, Lee Y, Zullo AR, Kiel DP, Dosa D, Mor V. Incidence of hip fracture in U.S. nursing homes. J Gerontol A Biol Sci Med Sci. 2016; 9(71):1230-1234.

3. Bergström U, Jonsson H, Gustafson Y, Pettersson U, Stenlund H, Svensson O. The hip fracture incidence curve is shifting to the right. Acta Orthop. 2009;80(5):520-524.

4. Brauer CA, Coca-Perraillon M, Cutler DM, Rosen AB. Incidence and mortality of hip fractures in the United States. JAMA. 2009;302(14): 1573-1579.

5. Smith GH, Tsang J, Molyneux SG, White TO. The hidden blood loss after hip fracture. Injury. 2011;42(2):133-135.

6. Kumar D, Mbako AN, Riddick A, Patil S, Williams P. On admission haemoglobin in patients with hip fracture. Injury. 2011;42(2):167-170.

7. Gruson KI, Aharonoff GB, Egol KA, Zuckerman JD, Koval KJ. The relationship between admission hemoglobin level and outcome after hip fracture. J Orthop Trauma. 2002;16(1):39-44.

8. Khan MA, Hossain FS, Ahmed I, Muthukumar N, Mohsen A. Predictors of early mortality after hip fracture surgery. Int Orthop. 2013;37(11): 2119-2124.

9. Bhaskar D, Parker MJ. Haematological indices as surrogate markers of factors affecting mortality after hip fracture. Injury. 2011;42(2): $178-182$.

10. Vochteloo AJ, Borger van der Burg BL, Mertens B, et al. Outcome in hip fracture patients related to anemia at admission and allogeneic blood transfusion: an analysis of 1262 surgically treated patients. BMC Musculoskelet Disord. 2011;12:262.

11. Foss NB, Kristensen MT, Kehlet H. Anaemia impedes functional mobility after hip fracture surgery. Age Ageing. 2008;37(2):173-178.
12. Shander A, Knight K, Thurer R, Adamson J, Spence R. Prevalence and outcomes of anemia in surgery: a systematic review of the literature. Am J Med. 2004;116(Suppl 7A):58S-69S.

13. Lawrence VA, Silverstein JH, Cornell JE, Pederson T, Noveck H, CarsonJL. Higher Hb level is associated with better early functional recovery after hip fracture repair. Transfusion. 2003;43(12):1717-1722.

14. Carson JL, Willett LR. Is a hemoglobin of $10 \mathrm{~g} / \mathrm{dL}$ required for surgery? Med Clin North Am. 1993;77(2):335-347.

15. Moran CG, Wenn RT, Sikand M, Taylor AM. Early mortality after hip fracture: is delay before surgery important? J Bone Joint Surg Am. 2005; 87(3):483-489.

16. Auron-Gomez M, Michota F. Medical management of hip fracture. Clin Geriatr Med. 2008;24(4):701-719.

17. Mitchell G, Hucker T, Venn R, Wakeling H, Forni L. Pathophysiology and clinical implications of perioperative fluid excess. Br J Anaesth. 2003;90(3):395; author reply 395-396.

18. Carson JL, Hill S, Carless P, Hébert P, Henry D. Transfusion triggers: a systematic review of the literature. Transfus Med Rev. 2002;16(3): 187-199.

19. Menon S, Kelly AM. How accurate is weight estimation in the emergency department? Emerg Med Australas. 2005;17(2):113-116.

20. Foss NB, Kehlet H. Hidden blood loss after surgery for hip fracture. $J$ Bone Joint Surg Br. 2006;88(8):1053-1059.

21. Nadler SB, Hidalgo JH, Bloch T. Prediction of blood volume in normal human adults. Surgery. 1962;51(2):224-232.

22. Odumala AO, Ayekoloye CI, Packer G. Predictors of excessive blood loss during operative treatment of hip fractures. J R Coll Surg Edinb. 2002;47(3):552-556.

23. McBride DJ, Stother IG. Blood transfusion requirements in elderly patients with surgically treated fractures of the femoral neck. $J R$ Coll Surg Edinb. 1988;33(6):311-313.

24. Carson JL, Poses RM, Spence RK, Bonavita G. Severity of anaemia and operative mortality and morbidity. Lancet. 1988;1(8588):727-729.

25. Kehlet H, Dahl JB. Anaesthesia, surgery, and challenges in postoperative recovery. Lancet. 2003;362(9399):1921-1928.
Clinical Interventions in Aging

\section{Publish your work in this journal}

Clinical Interventions in Aging is an international, peer-reviewed journal focusing on evidence-based reports on the value or lack thereof of treatments intended to prevent or delay the onset of maladaptive correlates of aging in human beings. This journal is indexed on PubMed Central, MedLine,

\section{Dovepress}

CAS, Scopus and the Elsevier Bibliographic databases. The manuscript management system is completely online and includes a very quick and fair peer-review system, which is all easy to use. Visit http://www.dovepress. com/testimonials.php to read real quotes from published authors. 